\title{
ARTICLE
}

\section{Medicine and Spirituality The role of love in the therapeutic process of HIVIAIDS sufferers in an African village}

\author{
Andrew Lightbown $\mathrm{MBA}^{\mathrm{a}}$ and Nicholas Fane BA MEd ${ }^{\mathrm{b}}$ \\ a Lecturer in Business and Business Ethics, University of Buckingham, UK \\ b Person-Centred Counsellor, Oxford Christian Institute for Counselling, Headington, Oxford, UK
}

\begin{abstract}
Drawing on research with HIV patients in the small rural Ugandan village of Kabubbu, this article explores the role that love plays in the overall therapeutic process of HIV sufferers, as they move from death's door to increased well-being. Since 1999 a Christian charity and its donors have supported Kabubbu. Quicken Trust acts as an intermediary between individual donors and recipients. The latter are identified by a locally managed N.G.O., the Kabubbu Development Project, with whom Quicken Trust has established a range of initiatives, one of which is an HIV centre. This article examines how loving relationships, expressed in different forms, are vital within the overall therapeutic process. We explore the role of love (agape) in these relationships, from the perspective of counsellors and most importantly sufferers, and theorise about the motives of charitable donors. We show how HIV sufferers truly "walk through the valley of the shadow of death"' and how, despite living with a death sentence as it were, sufferers find that life can take on a new meaning, including reassessing their attitudes towards dependants, community, death and the unknown. Increased well-being is, we argue, a manifestation of two distinct forms of love: in our terms, 'sympathetic or economic agape', and 'empathetic or vocational agape.” This article explores the vital, yet complementary, differences between these two forms of love.
\end{abstract}

\section{Keywords}

HIV, AIDS, Kabubbu, Quicken Trust, love, agape, sympathy, empathy, ‘economic-agape,' ‘vocational-agape,' counselling, medicine, therapeutic process, theirs, well-being, donors, beneficiaries, prayer.

\section{Correspondence Address}

Mr. Andrew Lightbown, School of Business, University of Buckingham, Hunter Street, Buckingham MK18 1EG, UK. Email: andrew.lightbown@buckingham.ac.uk

Accepted for publication: 21 January 2011

\section{Introduction}

In an earlier publication [1] we sought to examine the economic manifestations of charity, and people who had been given the gift of HIV treatment were one of four categories of beneficiary we interviewed. The reason that we came to believe that love plays a crucial role in the therapeutic process is because the sufferers told us so. Our starting point is their perspective, because it is their therapeutic process. Our research methodology is inductive and grounded. The narrative presented here is largely the result of the stories we heard from grateful recipients.

Narrative theory has had a significant impact on counselling practice in recent years. As James Nelson points out humans are "story-telling animals that judge what we do by the stories we inhabit." Not only do we interpret ourselves through our stories, but also, with Eric Berne [cf.2], we can see ourselves as the authors of our own "scripts", by which we live (and even die). Hearing and understanding the sufferers' stories has many advantages, as narrative also facilitates insights into cause and effect, with the most important being the requirement for a holistic approach. The stories we were privileged to hear, and the overall narrative we subsequently derive from these, testify to the importance of love (a virtue), working alongside medicine (a science), in the overall therapeutic process. Pope Benedict XVI [3], in a recent encyclical letter (Caritas in Veritate), has discussed the importance of a holistic approach to development and the importance of scientists cooperating with religious or spiritual leaders, and vice versa, in the promotion of overall well-being (the teleos of love), suggesting that 'human freedom is 
authentic only when it responds to the fascination of technology with decisions that are the fruit of moral responsibility.' that 'entranced by an exclusive reliance on technology, reason without faith is doomed to flounder in an illusion of its own omnipotence. Faith without reason risks being cut off from everyday life.'[3] The stories told by HIV sufferers of Kabubbu reveal the truth inherent in Benedict's claims.

Fieldwork reveals that love does not replace medicine or science, but that it certainly animates it. The HIV sufferers of Kabubbu time and again testified to the fact that the provision of medicine, paid for by sympathetic donors, was not sufficient of itself to improve their overall well-being, either in the sense of catering for their immediate medical needs, or by laying the foundations for growth in their spiritual, familial and communal relationships. Holistic well-being, it appears, is promoted by love enacted first through sympathy, and then empathy, thereby enhancing (or quickening) the contribution of modern medicine. We advocate a whole, person-centred approach to medicine solely because the HIV sufferers told us in their own terms that this is what they required from their therapeutic process. Sufferers need and require medicine and science, but they also require so much more. They are, after all, also social and spiritual entities, and their disease has impaired all facets of their life. To achieve overall well-being the therapeutic process must also pay attention to their spiritual and social relationships.

Reflective practitioners working alongside others with traumatic diseases also stress the importance of love. Vanier in his work with those with intellectual disabilities and Kitwood with his study of dementia patients are obvious examples. Writing from a psychiatrist's perspective, Rachel Freeth has identified a western tendency to medicalise the counselling process, and certainly it can sometimes become a "treatment" which is meted out to a "patient" by an authoritative (and sometimes authoritarian) expert, who is in a position of power. Holistic approaches, which accept that agapeistic love has a vital role to play in the therapeutic processes, promote solidarity, reverence and respect. Science and medicine in this sense serve rather than dominate the overall process.

\section{What is agape?}

Agape is a Greek word, by which the New Testament concept of charity is signified. Charity is an act of giving. C.S. Lewis [4] referred to it as gift-love, directed towards those that need-love. Agape is a specifically Christian theological concept that implies a radical form of giving of self, both materially and spiritually, for the benefit of another human being. Agape implies a lack of regard for self- interest, self-promotion or reciprocity. Anonymity is a characteristic of agapeistic love. Agape involves the giving away, or forgoing, of something of value, the willing acceptance of an opportunity cost. Agape, or charity, as distinct from philanthropy, can be regarded as a bottom-up person-to-person form of love. Agape is an attitude and an orientation as well as act. Donors, those offering economic or sympathetic agape, forgo or accept an economic opportunity cost and this is also the case with the counsellors providing empathetic, or vocational agape, for they frequently give freely of their time or choose to accept lower paid positions working with the sufferers in rural Kabubbu, in order to fulfil their vocation or calling. Our research is carried out on behalf of Quicken Trust and our understanding is framed within the Christian context. We stress that we are not seeking to compare Christianity with other faith perspectives and would welcome insights from the other faiths.

\section{Sympathy and Empathy contrasted}

We have previously, in (Re) Discovering Charity [1], used Thomas Oord's definition of the agape form of love as 'to act intentionally, in sympathetic response to the others (including God) to promote well-being.' Oord includes the divine in his definition because many theologies hold that it is in human and incarnational relationships that the divine is revealed. Agape is essentially a form of gift-love, or Christian charity, directed towards the other, or those who need love, irrespective of any emotional or genetic attachment, liking, shared interests and where demands for mutuality and reciprocity are marked by their absence. Purity of motive is therefore an essential component of agapeistic love. If the therapeutic process is to be effective in securing increased well-being all actors' involved need to adopt agapeistic attitudes.

Our research has revealed that HIV sufferers in Kabubbu require different actors to exercise love, essentially agapeistic in nature, at differing stages in the overall therapeutic process. The implication of this is that the definition we have previously provided may not be sufficiently tight, for we now know that HIV sufferers need some lovers to exercise their love through the medium of sympathy and others through empathy. We do not seek to rank sympathy and empathy, for both, as described by Wispe [5] are necessary. However it is important to note that the sympathetic response precedes the empathetic response. Sympathy, despite modern connotations with 'tea and sympathy' is a loving economic response to states of ill being. Indeed Adam Smith frequently referred to the exercise of what we might consider to be 'economic sympathy.'

We are driven to act sympathetically when we acknowledge the pain of the other, and where this makes us feel sufficiently uncomfortable to take action that is designed to improve the individual's state of well-being. Sympathy is the response that prompts giving. Sympathy is therefore akin to provisioning; sympathy is the emotion that prompts material investment in the well-being of the beloved other. In the case of the HIV sufferers in Kabubbu the sympathetic response provides for the medicine, 
hospital, and staff that can address the immediate and necessary medical needs. Individual charity is absolutely essential in the absence of a state funded clinic. Sympathy is, therefore, necessary. But it is not sufficient: if the therapeutic process is to be effective a different set of lovers are subsequently required to empathise with the sufferer.

So there is a need to move from sympathy to empathy. Drawing on the work of Carl Rogers, empathy is commonly used in counselling to describe the counsellor's ability "to sense the feeling and personal meaning of the client's experience.” We believe that empathy is also an appropriate word to use when providing spiritual support. The person centred counselling approach stresses the importance of empathy alongside congruence, where the counsellor seeks to experience, and attend to, the feelings and emotions as experienced by the client in a climate of total openness and honesty. This helps to distinguish empathy from sympathy, for where the empathetic response is one where the giver tries to feel as the sufferer, the sympathetic response occurs when the giver feels for the sufferer. HIV sufferers in Kabubbu told us, repeatedly, how important counselling was in the overall therapeutic process. By themselves the sufferers would simply have stopped taking the medical treatment that the sympathetic response had elicited, such was the pain they experienced during its early stages.

If there are guiding ethics that underpin both the sympathetic and empathetic agapeist they are reverence and solidarity. By reverence we mean total respect for all humans as uniquely created, and uniquely valuable, irrespective of mere circumstance. By solidarity we mean being fully alongside another person in their distress. We therefore offer this slightly revised definition of agapeistic love:

'To act intentionally to promote well-being, in solidarity with, and reverential response to, others.'

Reverence and solidarity are theological terms, or ethics, which both imply due respect and regard for each individual as a uniquely created being and therefore possessing inherent value. Stephen Post suggests that such love is sacramental in nature.

\section{Theological Perspective}

Love, care for the vulnerable and the treatment of the whole person are all central to Christian theology. Indeed, the whole-person approach to the therapeutic process is a theme that runs through both the gospel message, and an historical analysis of Christian mission, although historical analysis also shows that Christians have frequently failed to live up to the Gospel message. This leads us to say that the aspect of love known to Christians as agape affects the therapeutic process in a number of ways, and in particular is at the transformational heart of counselling.
That Jesus responded to the needs of the whole person is beyond doubt. A careful reading of the healings recorded in John Chapter 5 (The Healing at the Pool) and John Chapter 9 (The Healing of a Man Born Blind) show that Jesus was, in modern terms a person-centred healer. Jesus' healing ministry took place in public: it had to, as the blind and lame congregated by the temple and in other public spaces, in the hope of receiving alms and, perhaps, a miracle healing. Jesus was very much under the spotlight from two groups of people, the public at large who regarded the healings as a form of entertainment and the scribes and Pharisees, the 'regulators' of the day, who would presumably have preferred to see Jesus' healings being subject to an administrative and legal process, rather than being acts of love designed to meet both the material and spiritual needs of the patient.

These two accounts show that Jesus' primary concern was the person that he had healed, and John informs us that on both occasions, after he had been questioned by the 'regulators', Jesus quietly went back to visit the person whose medical needs he had previously attended to and, through love, began the process of addressing their spiritual and social needs. This was necessary because the physically and mentally ill were excluded from society on the basis that either they, or their parents, were inherently sinful. Jesus absolutely recognised that low self-esteem and social exclusion were inextricably bound up with physical and mental illness, hence the requirement to heal the whole man. Jesus knew that unless love, in its various forms, resided at the heart of the therapeutic process, the result would be that the powerful and educated would remain ill-informed and would continue to judge by mere appearances, good judgements would become impossible, and the patient's well-being would scarcely improve.

\section{Counselling perspective}

According to McLeod the term 'counselling' is applied sometimes loosely - to a spectrum of helping activities, ranging from the giving of information, through the provision of advice, to a core process of therapeutic change. Professional counsellors trained in the main western traditions might dispute whether the giving of information and advice are counselling activities, but it is undeniable that in common usage these can have a part to play in certain contexts. Particularly, perhaps, this is true in medical contexts, such as HIV/AIDS counselling, where the provision of information is inseparably linked to enabling the client to process this information in the midst of emotional turbulence.

The Joint United Nations Programme on HIV/AIDS [6] offers the following pragmatic, if somewhat utilitarian, view of the counselling process in relation to HIV/AIDS: "HIV counselling is a confidential dialogue between a client and a counsellor aimed at enabling the client to cope with stress and take personal decisions... [It] includes 
evaluating the personal risk of HIV transmission, and discussing how to prevent infection. It concentrates ... on emotional and social issues related to possible or actual infection with HIV and AIDS".

"With the consent of the client, counselling can be extended to spouses, sex partners and relatives" (based on the concept of shared confidentiality).

"A counsellor is a person trained in the skills of the job: listening to the client, asking supportive questions, discussing options, encouraging the client to make his or her own informed decisions, giving practical information and suggesting follow-up."

Humanistic, and especially person-centred, counsellors see counselling as a meeting of equals and this approach would certainly find favour in Christian theology. Tutu's ubuntu based approach and Benedictine spirituality being two obvious examples. For the person-centred counsellor, what Carl Rogers called unconditional positive regard is at the heart of the process: arguably, indeed, it is the process. Such an approach may be transformational at the deepest level. For the person-centred counsellor who is a Christian, this unconditional positive regard becomes wholly synonymous with the unconditional love known as agape, or in our terms empathetic or vocational agape.

It is becoming clear to those from other psychotherapeutic traditions that Rogers had a valuable point. In his seminal study which seeks an integration of Freud, Rogers, Gill and Kohut, Michael Kahn ${ }^{8}$ details the characteristics of the 'New Relationship' in counselling: genuineness, non-defensiveness, spontaneity, respect, understanding and empathy. We argue that all of these and more are present in agape.

Michael McMillan [7] draws attention to Brian Thorne's identification of how, in certain counselling situations and circumstances, there emerges an unforced "preparedness and an ability to move between the worlds of the physical, the emotional and the mystical.” He [ibid] goes on to quote Thorne's description of the experience:

"At such a moment I have no hesitation in saying that my client and I are caught up in a stream of love. Within this stream there comes an effortless or intuitive understanding... It sometimes seems that I receive my client whole and therefore possess a knowledge of him or her which does not depend on biographical data."

Further, Peter Gubi [8] associates Thorne and others with the view that:

"the therapeutic process, in itself, can be regarded as a spiritual journey, with spirituality being claimed to be the very essence of, and an inseparable part of, the counselling process."

These views, although stressing the importance of the emotional and the spiritual, do not in any sense relegate or diminish the importance of the physical, for it is recognised that the sufferer lives in the physical and material world, hopefully in a state of overall well-being.

The experience of clients in Kabubbu has often been of a very different kind of love from agape: the erotic love that has led their partners first of all to possess and then to betray and desert them. This betrayal can hurt deeply, even as much in some ways as the pain and fear of the illness, a betrayal particularly savage because of the joy and trust of sexual union. To be able to move on, a client may need, as Betty told us, to be able to forgive.

\section{Vocational agape, in Kabubbu}

Our research in Kabubbu suggests that the pattern of counselling there very much reflects the UNAIDS principles, as well as providing concrete examples of the presence of agape suffusing day to day practice. These examples lead us to share Brian Thorne's perception that authentic therapeutic relationships have the power to help people to become more Christ-like.

The nurse in charge of the Kabubbu HIV centre is young, single and deeply committed to those in her care. As a highly qualified and caring professional she would be able to command a high salary, providing her with the income to fund a comfortable lifestyle in Kampala. Instead she works in Kabubbu, for a vastly reduced salary (in excess of $50 \%$ less than what she could have earned), a real economic opportunity cost foregone. She regards her job as a real vocation, commenting that, "I am called on to do God's work in Kabubbu. HIV is a disease to be beaten and in the dignity and recovery, of every life that I encounter."

There are four HIV counsellors working in the community, offering professional agape to those in need. The counsellors are part time and unpaid; they therefore truly provide gift-love, to those who need-love. Two of the counsellors are HIV positive; one of them had full blown AIDS when he started on the medical regime and for the last ten years has, every day, handed on the baton of love to those in his community who most need it.

On average 50 people come forward for testing each month of which over $70 \%$ are women. About one in five of those tested are found to be positive. Stigma and fear stop many more people from coming forward for testing. Confronting stigma and fear is central to the counselling process and in encouraging others to accept the need for testing. Those tested are offered counselling irrespective of the results. Many of those who test negative are asked to come back for a second or even third test because a window exists during which the disease cannot be diagnosed.

The counsellors follow a family focused approach and urge each person tested to ask their partners to come forward for testing. In many cases counsellors engage in not only HIV counselling but family therapy as well, as the UNAIDS principles envisage. Those receiving counselling normally attend four or five individual, one to one, sessions. Thirty sufferers regularly attend monthly group meetings. Aware that many of the sufferers remain economically and socially isolated the counsellors have arranged various economic initiatives, which operate on a group basis: some of the women meet to make rush mats, for instance, whilst some of the male sufferers work 
together cultivating cabbages. Many of the sufferers have been rejected as outcasts and have no land to call their own, so in a spirit, which epitomises vocational agape, a plot of land was purchased by a loving member of the community for the sole use of the HIV sufferers.

The counsellors believe that there are seven issues that counselling is required to encompass:

- Addressing reality. 'In HIV counselling there is no deceiving: we deal with facts.'

- Disclosure - naming the disease and telling others. 'When you accept the reality you start to kill the stigma.

- $\quad$ Adherence - sticking to the drugs regime.

- Working with the disease - ensuring sufficient time for rest and recuperation.

- Health - especially diet and nutrition.

- Socio-economic - social and economic relationships.

- Education - engaging with others to reduce the reach and length of the sexual chain.

- None of these things can happen if the sufferers do not have complete trust in the counsellor, for so often in the past their trust in others has been abused. For this trust to be established the client has to experience the counsellor's empathy, be sure of his honesty and integrity and feel her unconditional positive regard or agape.

\section{The manifestations of love}

In "(Re)discovering Charity" [1], we gave the example of Margaret who told us that good counselling was "like having God by my side", and that through the gift of treatment she has "seen the Grace of God."

Following fieldwork undertaken in June 2009 further interviews were held with HIV sufferers in April 2010, the stories below are provided in order to highlight some of the characteristic manifestations arising from the totality (sympathetic or economic, and empathetic or vocational agape.)

Alice is a 37-year-old mother of two young children, and also looks after her 35-year-old brother. She has twice experienced the loss of abandonment, first by her mother when she was two, and more recently by her husband (who left after infecting her with HIV).

Although practical issues such as lack of finance and transport have led to her missing many sessions, Alice says she has found the business of counselling crucial in her battle against the disease, and the fear it generates. In peer group sessions in particular, she has found Obumu - the supportive love of fellow sufferers. She says that counselling has allowed her "to abandon thoughts that tomorrow I am going to die", and helped her to focus on the future and support of her children to whom she lovingly says, "Don't move carelessly."
The gift-love she has received has helped Alice to invest in the future of her own loved ones. One of Alice's deepest desires is simply to be a good mother, now this desire may be fulfilled.

Progress is often tentative and slow. 48 year-old Stephen and 59 year-old Katherine have been married for 24 years and have six children living in the home (two of their own and four grandchildren.) They have both been on an HIV programme for three years, though, like Alice they frequently failed to adhere to advised schedules and their drugs regime. Both have been subsistence farmers all their married lives, occasionally selling a small coffee crop, but in 2007 diversified into the goat business. Stephen and Katherine insist that their counselling needed to take place as a couple, for they also had to consider relationship issues. They have not as yet joined a broader HIV group but are considering doing so, as their trust in the counselling process and their ability to be open with each other and others gradually develops.

Stephen and Katherine's story reminds us of St. Paul's proclamation that 'love is patient.' Stephen and Katherine have enjoyed some economic gains, and the relationship is more stable, in time they may begin to experience greater social gains as well.

The person with HIV/AIDS follows a journey with many echoes of Jesus' passion journey. Betrayed and abandoned by those who were once trusted, stigmatised and vilified by neighbours, filled with fear, despair, hopelessness, bitterness and alienation. Too often this can lead to guilt and self-loathing, even occasionally the ultimate self-rejection of suicide. We recall 30-year-old Margaret describing to us how, after her husband's death, "I was chased out from his family. The people nearby all look down on me. They treat you like you were a stranger, and not a normal human being. My children are stigmatised by other children."

This had led to recurrent depression:

"The bad feeling inside me has come back: it is a spiritual thing, not a physical thing."

The reality is for sufferers such as Margaret that love is a necessity, for science and medicine can only address the 'physical thing.' They really can't address the 'spiritual thing' that Margaret herself regards as being of utmost importance.

40 year-old Betty lives with seven others in a house formerly owned by her deceased husband, who died of AIDS in 2002. He had many wives and infected Betty. Betty believes that her current state of good health is a product of drugs, counselling and forgiveness. She explains that 'at a certain point I had to learn to forgive myself and my husband.' When asked what she had to forgive herself for and she replied, 'My bitterness.' Betty has been on an HIV programme for five years - initially at Mulago and now in Kabubbu. Betty believes that the counsellors helped her 'defeat fear.' Betty is determined to be a good neighbour and do her bit to break the cycle of infection and despair. Everyone knows she has HIV and her children are 'so good at helping me to adhere,' to her 
drugs regime. Her children tell her: You are our mother and our father, keep up the drugs, we don't want you to die.' Betty's story demonstrates how love expressed through sympathy and empathy has led to improved health, increased self-esteem and the rebuilding of family.

Even in the presence of this love, Betty still finds it hard to join the HIV group, though she does, however, encourage others to come forward for testing and comments that people frequently refuse to accept their initial diagnosis, so she takes them to a nearby hospital for a second test. When the diagnosis is confirmed she brings her neighbours back to Kabubbu for drugs and counselling. Betty insists that HIV is 'a family illness,' and that you 'don't hide your sickness, you talk about it,' and that it is important to understand that HIV is 'a family illness.' Treatment, counselling, owning her disease and forgiving her perpetrator, have all contributed to Betty becoming a functioning and valuable member of society. The therapeutic process offers a route where sufferers may receive at least a temporary re-quickening of a dying body and through counselling a place where love, of self and neighbour, may begin to be re-experienced, hope regained and society rebuilt, for the fruits of agapeistic love, paradoxically, flow upstream.

\section{Prayer as a manifestation of love}

And, finally, what of prayer? Does prayer have any part to play in the therapeutic process? There are many counsellors, including counsellors who have a strong faith, who would consider prayer within counselling as inappropriate or unethical, and certainly any attempt to proselytise would be a serious breach of fundamental boundaries.

The issue is made more complex by widely differing perceptions of what "prayer" actually is. As Peter Gubi [8] points out, prayer can be seen inter alia as an encounter and communion with God, as an I/Thou relationship with an Other, as an experience of the absence of God, as a waiting in silence, as a reaching into one's spiritual centre. Gubi, like many others concludes that prayer is process rather than content.

We would suggest that here are two clear situations in which prayer in counselling may be both appropriate and ethically sound. The first is when there is prayer on behalf of the client (or counsellor or both) outside the counselling arena. The second is where the client's awareness of self is inextricably bound up with their faith. It was not uncommon in the village for clients to "live and breathe" their faith, in a way that is unusual in modern western society, and that would perhaps be uncomfortable (or unfamiliar) to the secular counsellor, but not to the counsellors in the village who recognise and accept that for many of their clients prayer is a regular and normal part of the way they exist in the world, and part of how they process their feelings and concerns. Surely the authentic processing of feelings and concerns is a fundamental requirement of an effective counselling process.

As Veronica, abandoned mother of four, commented: "I feel better, and a better mother, because now I can give my problems to God, and when I do the problem is lifted... My best prayer, one I learned from a close friend, is to have faith in God, and trust him fully."

And 28 year-old Joy, who was at breaking point, beyond coping, and on the point of abandoning her children, found a way forward when a counsellor gathered her up, prayed for her, and began to provide nurturing support:

"Her prayers and encouragement were so helpful. They made me feel strong and gave me the ability to resist."

As one of the counselling team told us, "Many AIDS sufferers develop fear spiritually, and are thinking of ending their lives." In response to this, the other counsellors interviewed believe that testimony and prayer are frequently integral to the counselling process, and another manifestation of agape. If such testimony and prayer strayed into proselytising, all agape (with its total respect of the other) would have vanished, and counselling would have become indoctrination, but appropriate boundaries apply, and this does not happen.

\section{Conclusion}

The stories told testify to the importance of love within the therapeutic process. Two different forms of essentially agapeistic love are required: economic agape and professional agape. Agape in both forms implies a radical giving of self both materially and spiritually. Agape can quite literally be the difference between life and death, for medicine by itself can only answer the sufferer's physical needs, whereas increased well-being is a consequence of improvements in the sufferer's physical, spiritual and social needs.

\section{References}

[1] Lightbown, A. and Fane, N. (2009). (Re) Discovering Charity. Buckingham U.K. U.B.P.

[2] Steiner, C. (1990). Scripts People Live. New York U.S.A. Grove Press p: 13.

[3] Benedict XVI (2009). 'Caritas in Veritate'-Encyclical Letter of His Holiness Benedict XVI

[4] Lewis, C.S (2002). The Four Loves, Signature Classics Edition. London U.K. Harper Collins.

[5] Wispe, L. (1986). The Distinction Between Sympathy and Empathy: To Call Forth A Concept, A Word Is Needed. Journal of Personality and Social Psychology, Volume 50, Number 2, pp 314-321.

[6] Toner, J. (1968). The Experience of Love. Washington U.S.A. Corpus.

[7] McMillan, M (2004). The Person-centred Approach to Therapeutic Change London, U.K. Sage.

[8] Gubi, P. (2009). Prayer in Counselling. London, U.K., Jessica Kingsley.

The International Journal of Person Centered Medicine Volume 1 Issue 1 pp 190-195 